Revista de Derecho

de la Pontificia Universidad Católica de Valparaíso

XXXI (Valparaíso, Chile, $2^{\circ}$ Semestre de 2008)

[pp. $163-185]$

\title{
RESPONSABILIDAD CIVIL DERIVADA DE ACCIDENTES DEL TRABAJO Y ENFERMEDADES PROFESIONALES: ASPECTOS RELEVANTES DE SU REGULACIÓN Y OPERATORIA ACTUAL*
}

[Civil Liability Derived from Work Accidents and Occupational Diseases: Relevant Aspects of its Regulation and Current Application]

\author{
José Luis Diez SchWerter** \\ Universidad de Concepción
}

\begin{abstract}
RESUMEN
ABSTRACT

En este trabajo se analiza la situación de la responsabilidad civil derivada de accidentes del trabajo y enfermedades profesionales en Chile, a la luz de recientes reformas legislativas con influencia en la materia, como lo son aquellas referidas al trabajo en régimen de subcontratación, al contrato de trabajo de servicios transitorios y al nuevo procedimiento laboral. También se analiza el impacto que tienen en el sector algunas sentencias recientes de nuestros tribunales superiores de justicia que han comenzado a apartarse de tendencias jurisprudenciales que parecían

This work analyzes the civil liability situation derived from work accidents and occupational diseases in Chile, in the light of recent legislative reforms with influence in the sector, as the ones referred to the transitory work services under the regime of subcontracting, for the labor agreement of transitory services and to the new labor procedure. It also analyzes the impact that some recent decisions in the area has in our superior courts of justice which have begun to be separated from jurisprudential trends that seem to be stable, in relevant aspects, such as the

* Este trabajo forma parte del proyecto de investigación Fondecyt (regular 2007) No 1070541, titulado "La responsabilidad civil derivada de accidentes del trabajo y enfermedades profesionales en Chile: análisis crítico de su funcionamiento y propuestas de racionalización”, del que el autor es el investigador responsable.

** Magíster en Derecho con mención en Responsabilidad Extracontractual (2000), y Doctor en Derecho (2003), en la Universidad de Roma “Tor Vergata". Profesor de Derecho civil de la Facultad de Ciencias Jurídicas y Sociales de la Universidad de Concepción. Dirección postal: Facultad de Ciencias Jurídicas y Sociales de la Universidad de Concepción, Barrio Universitario s/n, Casilla 160-C Correo 3, Concepción. Correo electrónico: jdiez@udec.cl
\end{abstract}


estables, en aspectos relevantes, como la vigencia y alcance de la responsabilidad subsidiaria y la transmisibilidad de la acción indemnizatoria por daño moral.

Palabras Clave: Responsabilidad Accidentes del trabajo - Enfermedades profesionales - Subcontratación - Servicios transitorios. force and scope of the subsidiary liability and transferability of the compensatory action caused by moral damage.

KeYwords: Liability - Work accidents - Occupational diseases.

\section{INTRODUCCIÓN}

En este trabajo nos referiremos a algunos problemas que han surgido en la responsabilidad civil derivada de accidentes del trabajo y enfermedades profesionales en Chile a consecuencia de reformas normativas recientes, así como por la configuración de nuevas líneas jurisprudenciales que han comenzado a apartarse de soluciones que parecían estables en importantes aspectos de esta materia.

Para proceder a ello hay que partir recordando que la Ley No 16.744 , de 1 de febrero de 1968, estableció un sistema de prestaciones de seguridad social exigible al verificarse un "accidente del trabajo" o "enfermedad profesional" (en los términos definidos en sus artículos 5 y 7); reconociendo, adicionalmente en su artículo 69, la posibilidad que surja responsabilidad civil "cuando el accidente o enfermedad se deba a culpa o dolo de la entidad empleadora o de un tercero", evento en el que, "sin perjuicio de las acciones criminales que procedan [...]. b) La víctima y las demás personas a quienes el accidente o enfermedad cause daño podrán reclamar al empleador o terceros responsables del accidente, también las otras indemnizaciones a que tengan derecho, con arreglo a las prescripciones del derecho común, incluso el daño moral'.

La determinación de los aspectos sustantivos y procesales en dichas hipótesis de responsabilidad ha dado lugar a sucesivas interpretaciones jurisprudenciales.

En lo que se refiere a los tiempos más recientes, y como consecuencia de la sentencia de 19 de agosto de 2003 dictada por la Cuarta Sala de la Corte Suprema ${ }^{1}$, nuestros tribunales fueron configurando dos estatutos sustanciales y adjetivos diversos para las acciones indemnizatorias derivadas de accidentes del trabajo y enfermedades profesionales, en atención a quien acciona en contra de la entidad empleadora ${ }^{2}$.

\footnotetext{
${ }^{1}$ Recaída en causa rol No 4859-2002, de dicha Corte.

${ }^{2} \mathrm{Al}$ respecto véase: DIEz SCHWERTER, José Luis, Victimas directas y por repercusión
} 
Así, se estimó que es la jurisdicción laboral la competente para conocer de las acciones indemnizatorias deducidas por el trabajador directamente afectado $^{3}$, ventilándose normalmente sus acciones a través del juicio ordinario del trabajo, invirtiéndose allí el peso de la prueba de la culpa, al entenderse que la sola ocurrencia del accidente del trabajo o enfermedad profesional implica incumplimiento al deber de protección u obligación de seguridad, incumplimiento que a su vez se presume culpable atendido lo dispuesto en el artículo 1547 inciso $3^{\circ} \mathrm{CCCh} .{ }^{4}$, por lo que sería carga del empleador demandado, "presunto responsable", "comprobar la justificación de su conducta", "justificar la causal de irresponsabilidad que invoque en su favor" (ya sea por ausencia de culpa o por haber concurrido una causa extraña $\left.{ }^{8}\right)$, entendiéndose mayoritariamente que responderá hasta

en la responsabilidad civil derivada de accidentes del trabajo o enfermedades profesionales en nuestra jurisprudencia reciente: del problema de la competencia a las distorsiones sustanciales, en Revista de Derecho 214 (Concepción, Universidad de Concepción, 2003 [pero 2005]), pp. 65-79, ahora, en Varas Braun, Juan Andrés - Turner SaElzer, Susan (coordinadores), Estudios de Derecho Civil. Jornadas Nacionales de Derecho Civil, Valdivia 2005 (Santiago, LexisNexis, 2005), pp. 563-583; y Diez SCHWERTER, José Luis, Responsabilidad civil por muertes en accidentes del trabajo: vacilaciones que persisten, en Corral Talciani, Hernán y Rodríguez Pinto, María Sara (coordinadores), Estudios de Derecho Civil (Santiago, LexisNexis, 2007), II, pp. 421-430.

${ }^{3}$ Todo ello en el entendido que teniendo aquí naturaleza contractual la responsabilidad civil, se les aplicaría la primera parte de la letra f) del artículo 420 del Código del Trabajo, es decir: "Serán de competencia de los Juzgados de Letras del Trabajo: [...] f) Los juicios en que se pretenda hacer efectiva la responsabilidad del empleador derivada de accidentes del trabajo o enfermedades profesionales [...]".

${ }^{4}$ En este sentido: Corte de Apelaciones de Santiago, 31 de enero de 2002, LexisNexis $\mathrm{N}^{\circ}$ identific. 25450 ("no puede dejar de recordarse que en materia contractual, como lo es el caso de autos, la culpa se presume"); Corte Suprema, 20 de enero de 2004, LexisNexis $\mathrm{N}^{\circ}$ identific. 29674 ("en lo atinente con la exigencia de la prueba del dolo o la culpa, como lo señala el recurrente, en la especie, se trata de una responsabilidad contractual, de manera que tal exigencia no es procedente"); Corte de Apelaciones de Antofagasta, 13 de diciembre de 2002, en Gaceta Jurídica [en adelante GJ.] 270 (Santiago, 2002), pp. 183 ss., también en LexisNexis $\mathrm{N}^{\circ}$ identific. 28660.

${ }^{5}$ Esta representativa expresión es usada por la Corte de Apelaciones de Antofagasta, 13 de diciembre de 2002, en GJ. 270 (Santiago, 2002), pp. 183 ss., también en LexisNexis $\mathrm{N}^{\circ}$ identific. 28660.

${ }^{6}$ Así: Corte de Apelaciones de Santiago, 2 de julio de 2002, en GJ. 265 (Santiago, 2002), pp. 85 ss. y en LexisNexis $\mathrm{N}^{\circ}$ identific. 28989; Corte de Apelaciones de Antofagasta, 13 de diciembre de 2002, en GJ. 270 (Santiago, 2002), p. 183 ss., también en LexisNexis $\mathrm{N}^{\circ}$ identific. 28660.

${ }^{7}$ Corte de Apelaciones de Santiago, 9 de julio de 2002, confirmada por Corte Suprema, 12 de mayo de 2003, ambas en Fallos del Mes 510 (Santiago, 2003), pp. 960 ss.

${ }^{8}$ En tal sentido se ha resuelto que "la irresponsabilidad pretendida por la recu- 
de culpa levísima ${ }^{9}$ en el cumplimiento del deber de protección u obligación de seguridad, exigible a su respecto en base a lo preceptuado en el artículo $184 \mathrm{CT}$. y a una frondosa normativa de diversa jerarquía que lo concreta o complementa ${ }^{10}$, pudiendo impetrarse la llamada "responsabilidad subsidiaria" del "dueño de la obra, empresa o faena" para hacer frente al pago de las indemnizaciones por accidentes del trabajo o enfermedades profesionales causados por dolo o culpa del contratista o subcontratista en virtud de lo que disponía el derogado artículo $64 \mathrm{CT} .{ }^{11}$, prescribiendo las

rrente [...], sólo puede ser reconocida si probare la concurrencia de caso fortuito o fuerza mayor o que el accidente en que perdiera la vida el trabajador se hubiese debido a un acto voluntario de la víctima o bien que las medidas de seguridad fueron debidamente arbitradas y que desplegó la diligencia debida en la práctica de las obligaciones que le imponía el contrato" (Corte de Apelaciones de Antofagasta, 13 de diciembre de 2002, en GJ. 270 (Santiago, 2002), pp. 183 ss., también en LexisNexis $\mathrm{N}^{\circ}$ identific. 28660. En el mismo sentido: Corte de Apelaciones de Concepción, 10 de julio de 2002, confirmada por Corte Suprema en fallo de 20 de enero de 2003, ambas en Fallos del Mes 506 (Santiago, 2003), pp. 5267 ss.). Al respecto véase: Diez SchwerTer, José Luis, La culpa del empresario por accidentes del trabajo: modernas tendencias jurisprudenciales, en Cuadernos de Extensión Jurídica 10 (Santiago, Universidad de los Andes, 2005), pp. 73-98.

${ }^{9}$ Así por ejemplo: Corte de Apelaciones de Santiago: 25 de noviembre de 1998, en GJ. 221 (Santiago, 1998), pp. 200 ss.; Corte Suprema, 27 de mayo de 1999, en Revista de Derecho y Jurisprudencia [en adelante RDJ.] 96 (Santiago, 1999) 2a parte, sección 3a, pp. 89 ss.; Corte de Apelaciones de Santiago, 17 de enero de 2000, en GJ. 235 (Santiago, 2000), pp. 199 ss.; Corte Suprema, 8 de agosto de 2000, en RDJ. 97 (Santiago, 2000), 2a parte, sección 3a ${ }^{a}$, pp. 152 ss.; Corte de Apelaciones de Santiago, 25 de octubre de 2000, en GJ. 245 (Santiago, 2000), pp. 233 ss.; Corte de Apelaciones de Concepción, 20 de mayo de 2002, en GJ. 270 (Santiago, 2002), pp. 160 ss. (citando a su vez fallo de la Corte Suprema publicado en RDJ. 96 (Santiago, 1999), $2^{a}$ parte, sección $3^{\mathrm{a}}$, pp. 89 ss.); Corte de Apelaciones de Concepción, 10 de julio de 2002, confirmada por Corte Suprema en fallo de 20 de enero de 2003, ambas en Fallos del Mes 506 (Santiago, 2003), pp. 5.267 ss., entre otros.

${ }^{10} \mathrm{Al}$ respecto véase: Diez SCHWERTER, José Luis, La culpa del empresario por accidentes del trabajo, cit. (n. 8), pp. 73-98.

${ }^{11}$ Así se ha resuelto que entre las obligaciones laborales a que se refiere el artículo 64 CT.: "naturalmente han de considerarse aquéllas que derivan del deber de cuidado que, respecto de la vida e integridad fisica de sus trabajadores, empece a todo empleador conforme lo disponen los artículos 184 del cuerpo legal ya mencionado y 69 de la Ley $N^{o}$ 16.744, y que se traducen en la necesidad de indemnizar, de manera satisfactoria, los daños que sufra la víctima y las demás personas que puedan verse afectadas por un accidente laboral' (Corte de Apelaciones de Santiago, 31 de enero de 2001, GJ. 248 (Santiago, 2001), pp. 211 ss.; en el mismo sentido ya antes: Corte Suprema, 16 de junio de 1997, en RDJ. 94 (Santiago, 1997), 2a parte, sección 3a, pp. 94 ss.) o que: “el dueño de la obra o faena, es responsable subsidiariamente de las obligaciones laborales, como es aquélla de seguridad y protección de los trabajadores fijada en el artículo 184 del Texto 
acciones indemnizatorias en un plazo de 5 años (ya aplicándose el plazo contemplado en el artículo 79 de la Ley No 16.744 de 1968 -tendencia mayoritaria-, ya en virtud del plazo del artículo 2515 CCCh. ${ }^{12}$, apreciándose la prueba según las reglas de la sana crítica, y todo ello bajo el influjo del "principio protector" al que alude la justicia y dogmática laboral ${ }^{13}$, entre otros aspectos relevantes. Además, en varias ocasiones se resolvió que el estatuto recién referido resultaba aplicable también a las demandas deducidas por causahabientes de trabajadores muertos en accidentes del trabajo que accionando iure hereditatis impetraban ante la justicia laboral el resarcimiento del daño moral que el causante habría experimentado

Laboral' (Corte Suprema, 8 de noviembre de 2000, LexisNexis $\mathrm{N}^{\circ}$ identific.17529); o que: "interpretando esta norma (artículo 64 del Código del Trabajo) al tenor de lo dispuesto en el artículo 19 CCCh., es dable sostener que es de carácter amplio, ya que al referirse a las obligaciones laborales, sin excluir a ninguna en particular, ni aludir a una en especial, no ha establecido distinción alguna y, evidentemente, ha entendido que quedan comprendidas todas aquellas obligaciones que tengan su origen en una relación laboral, de forma tal que la subsidiaridad no tiene limitación en cuanto a la naturaleza y origen de la obligación y, por lo mismo no está restringida sólo a las remuneraciones" (Corte de Apelaciones de Antofagasta, 20 de octubre de 2001, LexisNexis $\mathrm{N}^{\circ}$ identific. 25351).

${ }^{12}$ Aplicando el plazo de 5 años del artículo 79 de la Ley 16.744: Corte de Apelaciones de Santiago, 10 de julio de 1995, en GJ. 181 (Santiago, 1995), p. 138; Corte Suprema, 16 de junio de 1997, en RDJ. 94 (Santiago, 1997), 2a parte, sección 3a, pp. 94 ss.; Corte Suprema, 8 de agosto de 2000, en RDJ. 97, (Santiago, 2000) 2a parte, sección $3^{\mathrm{a}}$ pp. 152 ss. (rechazando expresamente aplicar el plazo de prescripción señalado en el artículo 480 CT.); Corte de Apelaciones de Concepción, 28 de agosto de 2002, en GJ. 266 (Santiago, 2002), pp. 210 ss. (rechazando expresamente aplicar el plazo de prescripción señalado en el artículo 480 CT.); Corte de Apelaciones de Concepción, 20 de mayo de 2002, autos rol No 887-2002 (reproduciendo considerandos de la sentencia de la Corte Suprema, 8 de agosto de 2000, citada anteriormente en la nota 10). Minoritariamente se ha entendido que el plazo es de 5 años pero contados desde que la obligación se hizo actualmente exigible, aplicando los artículos 2514 y 2515 CCCh. (así: Corte de Apelaciones de Santiago, 13 de octubre de 1992, en RDJ. 89 (Santiago, 1992), 2a parte, sección $3^{\text {a }}$ pp. 237 s.; y Corte de Apelaciones de Concepción, 12 de enero de 2000, rol laboral $\mathrm{N}^{\circ}$ 167-99, con comentario de Domínguez ÁGuILA, Ramón, Comentarios de Jurisprudencia, en Revista de Derecho 206 (Concepción, Universidad de Concepción, julio-diciembre 1999) [pero diciembre de 2000]), pp. 165-167.

${ }^{13}$ Sobre el "principio protector" y sus manifestaciones (como la regla "in dubio pro operario", "regla de la norma más favorable" y "regla de la condición más beneficiosa”) puede verse: Plá Rodríguez, Américo, Los principios del Derecho del Trabajo (Buenos Aires, Depalma, 1998) pp. 61-116; y en Chile muy recientemente: GAmonal Contreras, Sergio, Fundamentos de Derecho Laboral (Santiago, LexisNexis, 2008), pp. 104-124. 
antes de morir y cuya acción indemnizatoria les habría transmitido al momento de fallecer ${ }^{14}$.

Por su parte, si demanda indemnización de perjuicios derivado de un accidente del trabajo o enfermedad profesional una víctima por repercusión por su daño propio, se entendió que debe ocurrir a la vía civil correspondiente, pues calificadas sus acciones como de naturaleza civil extracontractual, se entienden quedar fuera de la competencia laboral ${ }^{15}$, ventilándose normalmente a través del juicio ordinario civil ${ }^{16}$, debiendo, por regla general, probar la culpa del empleador, sin que exista la posibilidad de hacer valer la "responsabilidad subsidiaria" del "dueño de la obra empresa o faena" (no contemplada en el régimen general de responsabilidad civil extracontractual), con un plazo de prescripción de sus acciones que, al menos para algunos, se entendió de cuatro años (aplicando el artículo 2332 CCCh. $)^{17}$, con limitaciones específicas a la prueba de testigos, y apreciándose en el juicio civil la prueba según el sistema de prueba legal o tasada, entre otras características importantes.

El reseñado esquema operativo se impuso, generalizadamente, desde la dictación por nuestra Corte Suprema de la referida sentencia de 19 agosto de 2003, no obstante, las evidentes distorsiones sustanciales que conlleva y el peligro adicional que genera de que puedan dictarse sentencias contradictorias por la justicia civil y laboral, en ciertas hipótesis en que ambas deberán conocer separadamente de acciones indemnizatorias derivadas del

${ }^{14}$ Explícitamente en este sentido: Corte de Apelaciones de Concepción, 12 de abril de 2004, rol No 4016-2003; y Corte de Apelaciones de Concepción, 28 de noviembre de 2005, rol No 2572-2005; e implícitamente: Corte Suprema, de 19 de agosto de 2003, donde se estableció que "la demandante es un tercero que no tiene ni ha acreditado relación laboral alguna con el demandado. No se trata de una cuestión entre trabajador y empleador, ni tampoco se ha ejercido acción en calidad de sucesora del dependiente afectado. Es decir, ciertamente entonces, la cónyuge sobreviviente del trabajador fallecido pretende hacer efectiva una responsabilidad de naturaleza extracontractual [...]", en GJ. 278 (Santiago, 2003), pp. 252 ss., considerando 6º.

${ }^{15}$ En base a lo preceptuado en la parte final de la letra f) del aludido artículo 420 CT., según tenor introducido por la Ley No 19.447, de 8 de febrero de 1996: Artículo 420: "Serán de competencia de los Juzgados de Letras del Trabajo: [...] f) los juicios en que se pretenda hacer efectiva la responsabilidad del empleador derivada de accidentes del trabajo o enfermedades profesionales, con excepción de la responsabilidad extracontractual a la cual le será aplicable lo dispuesto en el artículo 69 de la Ley No 16.744".

${ }^{16}$ Sin perjuicio que cumpliéndose los requisitos pudiera también intentarse como acción civil dentro del proceso penal.

${ }^{17}$ En tal sentido: Domínguez Águila, Ramón, con la colaboración de EscaloNa Riveros, Francisco, La prescripción extintiva. Doctrina y jurisprudencia (Santiago, Editorial Jurídica de Chile, 2004), pp. 412-415. 
mismo accidente del trabajo o enfermedad profesional ${ }^{18}$, como advertimos en su momento ${ }^{19}$.

\section{LAS NOVEDADES LEGALES}

\section{El impacto de la Ley $N^{\circ} 20.123$.}

La Ley No 20.123, de 16 de octubre de 2006 (que vino a regular el trabajo en régimen de subcontratación, el funcionamiento de las empresas de servicios transitorios y el contrato de trabajo de servicios transitorios), introdujo reformas que repercuten trascendentemente en la particular materia que ahora se analiza.

Entre ellas se pueden mencionar desde ya: i) la derogación del artículo 64 CT.; ii) la introducción de nuevos preceptos en dicho cuerpo normativo y en la Ley 16.744 que es necesario analizar respecto de la responsabilidad civil indemnizatoria derivada de accidentes del trabajo en el régimen de subcontratación; y iii) así como en el contrato de trabajo de servicios transitorios.

a) La derogación del artículo 64 CT. El artículo 64 CT. establecía: "El dueño de la obra, empresa o faena será subsidiariamente responsable de las obligaciones laborales y previsionales que afecten a los contratistas en favor de los trabajadores de éstos. También responderá de iguales obligaciones que afecten a los subcontratistas, cuando no pudiere hacerse efectiva la responsabilidad a que se refiere el inciso siguiente. [Inciso 2o] En los mismos términos, el contratista será subsidiariamente responsable de obligaciones que afecten a sus subcontratistas, en favor de los trabajadores de éstos. [inciso 30] El trabajador, al entablar la demanda en contra de su empleador directo, podrá también demandar subsidiariamente a todos aquellos que puedan responder en tal calidad de sus derechos. [Inciso 40] En los casos de construcción de edificios por un precio único prefijado, no procederán estas responsabilidades subsidiarias cuando el que encargue la obra sea una persona natural'.

$\mathrm{El}$ anotado precepto jugó un papel central en la materia ya que-como se adelantó- se entendió generalizadamente que en la jurisdicción laboral la llamada "responsabilidad subsidiaria" que afectaba al "dueño de la obra, empresa o faena" alcanzaba al pago de las indemnizaciones por accidentes

${ }^{18}$ Como sucedería, por ejemplo, en los casos de lesiones graves, en que el trabajador deberá accionar ante la justicia laboral y las eventuales víctimas por repercusión ante la justicia civil; o en el caso de muerte del trabajador, en que sus herederos deberán acudir a la justicia laboral si accionan iure hereditatis y a la justicia civil si lo hacen iure propio, a la cual podrán recurrir también otros eventuales damnificados indirectos no herederos.

${ }^{19} \mathrm{Al}$ respecto, véase: Diez SCHWERTER, José Luis, Victimas directas y por repercusión, cit. (n. 2), pp. 563-583. 
del trabajo o enfermedades profesionales causados por dolo o culpa del contratista o subcontratista, en el entendido que ellas estarían comprendidas dentro de "las obligaciones laborales" a que alude el referido artículo ${ }^{20}$.

$\mathrm{Si}$ bien dicha interpretación fue objeto de algunas críticas doctrinarias ${ }^{21}$, se impuso generalizadamente en nuestra práctica generando así una fuerte garantía para los trabajadores que sufrían daños derivados de un accidente del trabajo o enfermedad profesional, al posibilitarles hacer efectivos sus correspondientes créditos indemnizatorios no sólo en el patrimonio de su empleador directo que hubiera contribuido a generarlos con su dolo o culpa, sino que además les permitía dirigirse "subsidiariamente" (y por el total de esos créditos) en contra del "dueño de la obra, empresa o faena" por el sólo mandato del artículo 64 CT., siendo irrelevante a su respecto atribuirle (y probarle) culpa o dolo ${ }^{22}$.

Sin embargo, como se ha dicho, la Ley No 20.123, de 16 de octubre de 2006, procedió a derogar el referido artículo ${ }^{23}$, y en su lugar se aplican

${ }^{20} \mathrm{Al}$ respecto, véase a jurisprudencia citada en la nota 11 .

${ }^{21}$ Así por ejemplo: Zelaya Etchegaray, Pedro, Responsabilidad subsidiaria del dueño de obra por los accidentes y daños experimentados por el trabajador del contratista, en Cuadernos de Extensión Jurídica 10 (Santiago, Universidad de los Andes, 2005) pp. 99-122; Zelaya Etchegaray, Pedro, Responsabilidad subsidiaria del dueño de la obra, empresa o faena por los daños causados al trabajador de contratista o subcontratista (Naturaleza y extensión de la responsabilidad del artículo 64 del Código del Trabajo: un análisis dogmático y jurisprudencial), en RDJ. 101 (Santiago, 2004) 2, 2a parte, pp. 25-44. Un acabado estudio sobre los alcances dogmáticos de esta responsabilidad en: Peña González, Carlos y Pizarro Wilson, Carlos, Informe en Derecho sobre la responsabilidad subsidiaria del dueño de la obra, en Revista Chilena de Derecho Privado 2 (Santiago, Fundación Fernando Fueyo, 2004), pp. 152 ss.

${ }^{22}$ En este sentido se resolvió, por ejemplo, que la responsabilidad subsidiaria que establecía el derogado artículo 64 del Código del Trabajo para el "dueño de la obra empresa o faena", "reconoce como único y suficiente factor de atribución la titularidad dominical de la persona a quien se pretende hacer efectivo el deber de responder, sobre esa obra, empresa of faena; en otros términos, establecida la responsabilidad del contratista en la ocurrencia del accidente del trabajo, responde de manera subsidiaria quien encargó la ejecución de la obra sin que, respecto de éste, sea necesario entrar a considerar elementos subjetivos de imputabilidad, como son el dolo o la culpa, sea en el accidente mismo asi como en la celebración del correspondiente contrato de obra" (Corte de Apelaciones de Santiago, 31 de enero de 2001, GJ. 248 (Santiago, 2001), pp. 211 ss.; palabras que, a su vez, han sido citadas en otros fallos, como por ejemplo: Corte de Apelaciones de Concepción, 24 de septiembre de 2007, rol N 138-2007; Corte de Apelaciones de Chillán, 6 de noviembre de 2007, rol No 70-2007; y Corte de Apelaciones de Concepción, 4 de diciembre de 2007, rol N 405-2007).

${ }^{23}$ El artículo segundo transitorio de la Ley No 20.123, publicada el 16 de octubre de 2006, estableció que la derogación del artículo 64 CT. regirá a contar de 90 días después de su publicación. 
ahora una serie de nuevos preceptos que ella introdujo, diversos según se trate del régimen de subcontratación o del contrato de trabajo de servicios transitorios, como seguidamente se analizará.

b) La responsabilidad indemnizatoria por accidentes del trabajo o enfermedades profesionales en el régimen de subcontratación. En relación con esta hipótesis hay que tener presente el nuevo artículo 183 E introducido al Código del Trabajo por la Ley $\mathrm{N}^{\circ}$ 20.123. Dispone esta norma: "Sin perjuicio de las obligaciones de la empresa principal, contratista y subcontratista respecto de sus propios trabajadores en virtud de lo dispuesto en el artículo 184, la empresa principal deberá adoptar las medidas necesarias para proteger eficazmente la vida y salud de todos los trabajadores que laboran en su obra, empresa of faena, cualquiera sea su dependencia, en conformidad a lo dispuesto en el artículo 66 bis de la ley $N^{\circ}$ 16.744 y el artículo $3^{\circ}$ del decreto supremo $N^{\circ} 594$, de 1999, del Ministerio de Salud. [inciso 20] En los casos de construcción de edificaciones por un precio único prefijado, no procederán las obligaciones y responsabilidades señaladas en el inciso precedente, cuando quien encargue la obra sea una persona natural. [inciso $3^{\circ}$ ] Sin perjuicio de los derechos que se reconocen en este Párrafo $1^{\circ}$ al trabajador en régimen de subcontratación, respecto del dueño de la obra, empresa o faena, el trabajador gozará de todos los derechos que las leyes del trabajo le reconocen en relación con su empleador".

De este precepto se desprende, entonces, que para analizar la responsabilidad civil derivada de accidentes del trabajo o enfermedades profesionales dentro del trabajo en régimen de subcontratación se debe hacer una distinción:

i) Tratándose de la responsabilidad del contratista y subcontratista, estos responden "respecto de sus propios trabajadores en virtud de lo dispuesto en el artículo 184" del Código del Trabajo, norma que a su vez los obliga "a tomar todas las medidas necesarias para proteger eficazmente la vida y salud" de éstos, "manteniendo las condiciones adecuadas de higiene y seguridad en las faenas, como también los implementos necesarios para prevenir accidentes $y$ enfermedades profesionales" y debiendo "prestar o garantizar los elementos necesarios para que los trabajadores en caso de accidente o emergencia puedan acceder a una oportuna y adecuada atención médica, hospitalaria y farmacéutica".

En este aspecto el nuevo artículo 183 E CT. nada innova en relación con la regulación anterior, pues el texto del aludido artículo $184 \mathrm{CT}$. se ha mantenido inalterado luego de la dictación de la Ley $\mathrm{N}^{\circ} 20.123$.

ii) En lo que respecta a la responsabilidad de la empresa principal, la Ley $\mathrm{N}^{\circ} 20.123$ introdujo aspectos destacables, pues derogando la responsabilidad "subsidiaria" del dueño de la obra, empresa o faena contemplada 
en el antiguo artículo 64 CT., estableció ahora expresamente en el inciso $1^{\circ}$ del nuevo artículo $183 \mathrm{E}$ de este cuerpo legal como obligación directa de la empresa principal el "adoptar las medidas necesarias para proteger eficazmente la vida y salud de todos los trabajadores que laboran en su obra, empresa ofaena, cualquiera sea su dependencia, en conformidad a lo dispuesto en el artículo 66 bis de la ley $N^{\circ} 16.744$ y el artículo $3^{\circ}$ del decreto supremo No 594, de 1999, del Ministerio de Salud"24.

En todo caso en lo que atañe al reenvío que se hace allí al artículo $3^{\circ}$ del Decreto supremo No 594, de 1999, del Ministerio de Salud, tampoco representa una mayor novedad en nuestro ordenamiento jurídico, pues dicha norma ya existía al dictarse la Ley $\mathrm{N}^{\circ} 20.123$, estableciendo al efecto que: "La empresa está obligada a mantener en los lugares de trabajo las condiciones sanitarias y ambientales necesarias para proteger la vida y salud de los trabajadores que en ellos se desempeñan, sean éstos dependientes directos suyos o lo sean de terceros contratistas que realizan actividades para ella".

Lo que sí constituye una innovación es la referencia al nuevo artículo 66 bis de la Ley No 16.744 introducido también por la Ley No 20.123, precepto que en su inciso $1^{\circ}$ dispone que: "Los empleadores que contraten o subcontraten con otros la realización de una obra, faena o servicios propios de su giro, deberán vigilar el cumplimiento por parte de dichos contratistas o subcontratistas de la normativa relativa a higiene y seguridad", añadiendo que deberán para ello implementar un "sistema de gestión de la seguridady salud en el trabajo para todos los trabajadores involucrados, cualquiera que sea su dependencia, cuando en su conjunto agrupen a más de 50 trabajadores" (inciso $\left.1^{\circ}\right)^{25}$.

${ }^{24} \mathrm{La}$ existencia de responsabilidad "directa" en este ámbito en el artículo $183 \mathrm{E}$ CT. ha sido reconocida expresamente en Dictamen $N^{\circ} 141 / 05$ de la Dirección del Trabajo, de 10 de enero de 2007; y en doctrina: LANATA FuENZALIDA, Ruth Gabriela, El contrato de trabajo como negocio jurídico en la legislación chilena (Rosario, tesina de maestría en Derecho privado, Universidad Nacional de Rosario, 2007), p. 246250; Prado López, Pamela, Crítica a la configuración de la responsabilidad civil de la empresa principal y de la empresa usuaria en la Ley $N^{\circ} 20.123$, en GUZMÁN BRITO, Alejandro (editor científico), Estudios de Derecho Civil III. Jornadas Nacionales de Derecho Civil, Valparaíso 2007 (Santiago, Legal, Publishing, 2008), pp. 865-870; y Ugarte Cataldo, José Luis, El nuevo derecho del trabajo, (Santiago, Legal Publishing, 2008) p. 101.

${ }^{25}$ El Reglamento sobre la aplicación del artículo 66 bis de la Ley $\mathrm{N}^{\circ} 16.744$ sobre la gestión de la seguridad y salud en el trabajo en obras, faenas o servicios que indica (aprobado por Decreto supremo No 76 del Ministerio del Trabajo y Previsión Social, publicado en el Diario Oficial de 18 de enero de 2007), dispuso en su artículo $4^{\circ}$ que: "Para los efectos de este reglamento, se entenderá por obra, faena o servicios propios de su giro todo proyecto, trabajo o actividad destinado a que la empresa principal desarrolle sus operaciones o negocios, cuya ejecución se realice bajo su responsabilidad, 
El referido artículo 66 bis añade en su inciso $2^{\circ}$ que: "Para la implementación de este sistema de gestión, la empresa principal deberá confeccionar un reglamento especial para empresas contratistas y subcontratistas, en el que se establezca como minimo las acciones de coordinación entre los distintos empleadores de las actividades preventivas, a fin de garantizar a todos los trabajadores condiciones de higiene y seguridad adecuadas. Asimismo, se contemplarán en dicho reglamento los mecanismos para verificar su cumplimiento por parte de la empresa mandante y las sanciones aplicables".

Finalmente el inciso $3^{\circ}$ de este nuevo artículo 66 bis de la Ley $\mathrm{N}^{\circ}$ 16.744 agrega que: "Asimismo, corresponderá al mandante, velar por la constitución y funcionamiento de un Comité Paritario de Higiene y Seguridad y un Departamento de Prevención de Riesgos para tales faenas, aplicándose a su respecto para calcular el número de trabajadores exigidos por los incisos primero y cuarto, del artículo 66, respectivamente, la totalidad de los trabajadores que prestan servicios en un mismo lugar de trabajo, cualquiera sea su dependencia. Los requisitos para la constitución y funcionamiento de los mismos serán determinados por el reglamento que dictará el Ministerio del Trabajo y Previsión Social", lo cual fue cumplido por medio del Decreto supremo No 76, del Ministerio del Trabajo y Previsión Social (publicado en el Diario Oficial de 18 de enero de 2007), con el cual se aprobó el "Reglamento sobre la aplicación del artículo 66 bis de la Ley $N^{\circ} 16.744$ sobre la gestión de la seguridad y salud en el trabajo en obras, faenas o servicios que indica".

Así las cosas, existiendo ahora una obligación directa para la empresa principal de "adoptar las medidas necesarias para proteger eficazmente la vida y salud de todos los trabajadores que laboran en su obra, empresa o fae$n a$ " (en los términos señalados precedentemente) y alcanzando ella a los trabajadores de sus contratistas o subcontratistas, surge a continuación el problema de determinar la naturaleza de la responsabilidad que le asiste en caso de que incumpla culpable o dolosamente dicha obligación directa y ese incumplimiento sea la causa de un accidente del trabajo o enfermedad profesional que ocasione perjuicios a un trabajador de un contratista o subcontratista y éste le demande su resarcimiento ${ }^{26}$.

Sobre el particular el artículo 69 de la Ley $\mathrm{N}^{\circ} 16.744$ no aporta ante-

en un área o lugar determinado, edificada o no, con trabajadores sujetos a régimen de subcontratación".

${ }^{26} \mathrm{Si}$ quien demanda a la empresa principal o al contratista o subcontratista es una víctima indirecta (pariente o cercano del trabajador directamente afectado), por su daño propio, la responsabilidad será de naturaleza civil extracontractual y de competencia de la jurisdicción civil pues el artículo 420 letra f) CT. excluye precisamente las hipótesis de responsabilidad extracontractual de la competencia de los Jueces de Letras del Trabajo. 
cedentes decisivos, ya que simplemente se limita a establecer el derecho a la indemnización para el trabajador afectado por un accidente del trabajo atribuible a culpa o dolo de la entidad empleadora o de un tercero, reenviando "a las prescripciones del Derecho común" para la solución de los aspectos sustanciales involucrados (letra b).

$\mathrm{Al}$ respecto, y desde el punto de vista del "Derecho común" de la responsabilidad civil dos son, al menos, las formas de interpretación que pueden surgir. Por un lado, entender que no existiendo vinculación contractual directa entre la empresa principal y los trabajadores de su contratista o subcontratista la responsabilidad civil subsiguiente es de naturaleza extracontractual y regida por consiguiente por el título $35^{\circ}$ del libro IV CCCh. ${ }^{27}$. O, por el contrario (y como ya se ha planteado), "calificar a la responsabilidad de la empresa principal como de carácter contractual" en atención a que el artículo 183 E CT. contemplaría "una excepción legal al efecto relativo de los contratos, agregado al hecho que estamos ante contratos vinculados (el contrato celebrado entre la empresa principal y la contratista; y el contrato de trabajo que une a la contratista con sus trabajadores), en atención a la especialidad de la relación laboral, sobre todo bajo esta modalidad"28.

La complejidad del problema planteado abrirá, de seguro, un fuerte debate doctrinario y jurisprudencial, aunque hasta el momento no hemos encontrado sentencias que se pronuncien sobre el particular.

Y la solución que al respecto se siga repercutirá en la fijación de varios de los elementos estructurales de la responsabilidad indemnizatoria de la empresa principal en este ámbito, pues sabido es que en Chile tanto la responsabilidad civil contractual como la extracontractual presentan diferencias importantes. Aunque, en todo caso, cabe destacar que en cualquiera de estos regímenes, la regla general es que se responda subjetivamente: ya por la comisión de un delito o cuasidelito civil (en la responsabilidad extracontractual), ya por el incumplimiento doloso o culposo de un contrato (en la responsabilidad contractual), lo que constituye una situación muy diversa a la responsabilidad puramente "dominical" que, como se ha visto, fue impuesta "al dueño de la obra, empresa o faena" por una parte significativa de nuestra jurisprudencia en base al derogado artículo 64 CT. ${ }^{29}$.

${ }^{27}$ En tal sentido: LanATA FuENZALIDA, Ruth Gabriela, El contrato de trabajo como negocio jurídico en la legislación chilena, cit. (n. 24), pp. 249-250.

${ }^{28}$ Así lo ha sostenido: Prado López, Pamela, Crítica a la configuración de la responsabilidad civil de la empresa principal y de la empresa usuaria en la Ley $N^{\circ} 20.123$, cit. (n. 24), p. 867.

${ }^{29} \mathrm{Al}$ respecto se ha sostenido que la responsabilidad solidaria y subsidiaria que, afecta a la empresa principal respecto de las obligaciones laborales y pre- 
Por otro lado, en lo que atañe a la competencia para conocer de las acciones indemnizatorias que se deduzcan en contra del empleador directo y de la empresa principal en esta hipótesis cabe concluir que ésta corresponderá a la jurisdicción laboral, desde que, por una parte, al artículo 420 letra f) CT., dispone que: "Serán de competencia de los Jueces de Letras del Trabajo: [...] f) Los juicios en que se pretenda hacer efectiva la responsabilidad del empleador derivada de accidentes del trabajo o enfermedades profesionales [...]" (regla aplicable para fijar la competencia para conocer de las acciones indemnizatorias deducidas por el trabajador directamente afectado en contra de su empleador), en tanto que conforme al inciso $4^{\circ}$ del nuevo artículo 183 B CT.: "El trabajador, al entablar la demanda en contra de su empleador directo, podrá hacerlo en contra de todos aquellos que puedan responder de sus derechos, en conformidad a las normas de este Párrafo", y precisamente fundado en el incumplimiento de la obligación

visionales de dar (conforme, respectivamente, a los artículos 183 B y 183 C, y 183 D CT., introducidos por la Ley No 20.123), no comprendería el pago de indemnizaciones de perjuicios a que sea condenada la empresa contratista por su propia infracción a la obligación de seguridad. Así: Prado López, Pamela, Crítica a la configuración de la responsabilidad civil de la empresa principal y de la empresa usuaria en la Ley $N^{\circ} 20.123$, cit. (n. 24), pp. 868 s.; LANATA FuENZALIDA, Ruth Gabriela, El contrato de trabajo como negocio jurídico en la legislación chilena, cit. (n. 24), pp. 230-231, respecto de la responsabilidad solidaria. Desde ya la Dirección del Trabajo en Dictamen No 141/05, de 10 de enero de 2007, dejó expresamente señalado que "la responsabilidad solidaria que asiste a la empresa principal y al contratista por las obligaciones laborales de dar en favor de los trabajadores del contratista o subcontratista, según corresponda, alcanzará a todas aquellas obligaciones que, derivando de los contratos individuales o colectivos de trabajo o del Código del Trabajo y sus leyes complementarias, consistan en el pago de una suma de dinero determinada"; en tanto que respecto de las "obligaciones previsionales", se añade que "la circunstancia que el artículo 183-B, en comento, haya circunscrito la responsabilidad de la empresa principal o del contratista sólo a las obligaciones de dar, no asi a las de hacer, carácter que revisten las obligaciones de prevención de accidentes del trabajo y enfermedades profesionales a que se alude en el dictamen $N^{\circ}$ 544/32, precedentemente citado, forzoso es convenir que a la luz de la nueva normativa que se contiene en el citado artículo 183-B, la responsabilidad solidaria de la empresa principal y el contratista sólo alcanzará al pago de las cotizaciones de seguridad social de los trabajadores de que se trata". Por lo demás cabe recordar que fue producto del Veto Presidencial que en el artículo 183 B se agregó la expresión "de dar", consignándose expresamente que ello estuvo motivado por el hecho que las normas aprobadas por el $\mathrm{H}$. Congreso "podían suponer una extensión en el ámbito de las obligaciones de responsabilidad de la empresa principal a las obligaciones de hacer 0 a las obligaciones de dar derivadas del cumplimiento por equivalencia de las obligaciones de hacer", lo que se habría querido evitar con la referida inclusión. 
que establece el artículo $183 \mathrm{E}$-que integra ese párrafo- es que se va a demandar a la empresa principal ${ }^{30}$.

Ahora, si el trabajador del contratista o subcontratista demanda exclusivamente a la empresa principal por este tipo de responsabilidad indemnizatoria, nos encontraremos ante una hipótesis respecto de la cual resulta inaplicable la regla de competencia señalada en el inciso $4^{\circ}$ del artículo $183 \mathrm{~B}$, pues, como se ha visto, ella parte del presupuesto que se demande también al empleador directo. Y en atención al artículo 420 letra f) CT., resultaría que la competencia de los Juzgados de Letras del Trabajo alcanza sólo a "los juicios en que se pretenda hacer efectiva la responsabilidad del empleador derivada de accidentes del trabajo o enfermedades profesionales, con excepción de la responsabilidad extracontractual a la cual le será aplicable lo dispuesto en el artículo 69 de la ley $N^{\circ}$. 16.744", por lo que si el trabajador del contratista o subcontratista demanda exclusivamente a empresa principal debería hacerlo ante la jurisdicción civil.

Ello, en todo caso, a menos que pudiera entenderse que en base al amplísimo inciso final del artículo 183 E el trabajador del contratista o subcontratista pueda demandar a la empresa principal en la jurisdicción laboral, en el entendido que ese es un derecho que tiene respecto de su empleador directo, y en conformidad a la referida norma: "Sin perjuicio de los derechos que se reconocen en este Párrafo $1^{\circ}$ al trabajador en régimen de subcontratación, respecto del dueño de la obra, empresa o faena, el trabajador gozará de todos los derechos que las leyes del trabajo le reconocen en relación con su empleador" 31.

c) La responsabilidad indemnizatoria por accidentes del trabajo o enfermedades profesionales en el contrato de trabajo de servicios transitorios. En relación con esta hipótesis cabe tener presente el nuevo artículo 183-AB introducido al Código del Trabajo por la Ley $N^{\circ}$ 20.123. Señala esta norma: "La usuaria será subsidiariamente responsable de las obligaciones laborales y previsionales que afecten a las empresas de servicios transitorios a favor de los trabajadores de éstas, en los términos previstos en este Párrafo. [Inciso 20] No obstante lo dispuesto en el inciso precedente, será de responsabilidad directa de la usuaria el cumplimiento de las normas referidas a la higiene y seguridad en el trabajo, incluidas las disposiciones legales y reglamentarias relativas al Seguro Social contra Riesgos de Accidentes del Trabajo y Enfermedades Profesionales de la ley No 16.744, especialmente las medidas de prevención de riesgos que deba adoptar respecto

\footnotetext{
${ }^{30}$ Agradezco esta observación al Profesor de Derecho laboral de la Universidad de Concepción, Sr. Patricio Mella Cabrera.

${ }^{31}$ Cfr. Lanata Fuenzalida, Ruth Gabriela, El contrato de trabajo como negocio jurídico en la legislación chilena, cit. (n. 24), p. 250.
} 
de sus trabajadores permanentes. Asimismo, deberá observar lo dispuesto en el inciso tercero del artículo 66 bis de la ley $N^{\circ} 16.744$. [Inciso 3] Para efectos de dar cumplimiento a lo dispuesto en el artículo 76 de la ley $N^{o} 16.744$, la usuaria denunciará inmediatamente al organismo administrador al que se encuentra afiliada o adherida la respectiva empresa de servicios transitorios, la ocurrencia de cualquiera de los hechos indicados en la norma legal antes citada. Al mismo tiempo, deberá notificar el siniestro a la empresa de servicios transitorios. [Inciso $4^{\circ}$ ] Serán también de responsabilidad de la usuaria, las indemnizaciones a que se refiere el artículo 69 de la ley $N^{o}$ 16.744. Sin perjuicio de lo anterior, la empresa de servicios transitorios deberá constatar que el estado de salud del trabajador sea compatible con la actividad especifica que desempeñará.

El precepto anotado deja entonces establecida expresamente aquí una "responsabilidad directa de la usuaria" en el "cumplimiento de las normas referidas a la higiene y seguridad en el trabajo, incluidas las disposiciones legales y reglamentarias relativas al Seguro Social contra Riesgos de Accidentes del Trabajo y Enfermedades Profesionales de la Ley No 16.744, especialmente las medidas de prevención de riesgos que deba adoptar respecto de sus trabajadores permanentes. Asimismo, deberá observar lo dispuesto en el inciso tercero del artículo 66 bis de la Ley $N^{\circ} 16.744$ ", añadiendo expresamente además que "serán también de responsabilidad de la usuaria, las indemnizaciones a que se refiere el artículo 69 de la Ley No 16.744. Sin perjuicio de lo anterior, la empresa de servicios transitorios deberá constatar que el estado de salud del trabajador sea compatible con la actividad especifica que desempeñará".

Surgirá aquí también entonces el problema de determinar cuál es la naturaleza de la obligación indemnizatoria que le asistirá a la empresa usuaria cuando su contravención culposa o dolosa a la "responsabilidad directa" que le asiste en base al artículo $183 \mathrm{AB}$ sea causa de un accidente del trabajo o enfermedad profesional que afecte a un trabajador de la empresa de servicios transitorios y éste le demande el resarcimiento de los perjuicios sufridos ${ }^{32}$.

Sobre el particular el artículo 69 de la Ley $N^{\circ} 16.744$ no aporta antecedentes decisivos, ya que simplemente se limita a establecer el derecho a la indemnización para el trabajador afectado por un accidente del trabajo atribuible a culpa o dolo de la entidad empleadora o de un tercero, re-

${ }^{32}$ Si quien demanda a la empresa usuaria o a la empresa de servicios transitorios es una víctima indirecta (pariente o cercano del trabajador directamente afectado) por su daño propio, la responsabilidad será de naturaleza civil extracontractual y de competencia de la jurisdicción civil pues el artículo 420 letra f) CT. excluye precisamente las hipótesis de responsabilidad extracontractual de la competencia de los Jueces de Letras del Trabajo. 
enviando "a las prescripciones del Derecho común" para la solución de los aspectos sustanciales involucrados (en su letra b).

Desde el punto de vista del "Derecho común" de la responsabilidad civil dos serán aquí también, las alternativas de interpretación que pueden surgir. Por un lado, entender que no existiendo vinculación contractual directa entre la empresa usuaria y los trabajadores suministrados la responsabilidad civil subsiguiente es de naturaleza extracontractual y regida por consiguiente por el título $35^{\circ}$ del libro IV CCCh. O, por el contrario (y como ya se ha planteado), estimar que la responsabilidad de la empresa usuaria es de carácter contractual en atención a que el artículo 183 AB CT. contemplaría "una nueva manifestación de una excepción legal al efecto relativo del contrato", unido a que el trabajador suministrado estaría sometido a una "doble subordinación" (un "empleador formal, que es la empresa de servicios transitorios, y a un empleador sustancial que es la usuaria"), a la existencia de contratos relacionados, y a las nociones de cesión de contrato y estipulación a favor de otro ${ }^{33}$. Tampoco hemos encontrado jurisprudencia que se haya pronunciado sobre el particular.

Finalmente cabe consignar que las demandas indemnizatorias que por este tipo de responsabilidad puedan deducirse en contra de la empresa usuaria por los trabajadores de esta última deberán entablarse siempre ante los Juzgados de Letras del Trabajo, se accione o no conjuntamente en contra de la empresa de servicios transitorios, desde que el nuevo artículo 183 H CT., introducido por la Ley No 20.123, dispone expresamente que "Las cuestiones suscitadas entre las partes de un contrato de trabajo de servicios transitorios, o entre los trabajadores y la o las usuarias de sus servicios, serán de competencia de los Juzgados de Letras del Trabajo".

2. Un impacto del nuevo procedimiento laboral.

A partir de la Ley $N^{\circ} 20.087$ (publicada en el Diario Oficial del 3 de

${ }^{33}$ En tal sentido: Prado López, Pamela, Crítica a la configuración de la responsabilidad civil de la empresa principal y de la empresa usuaria en la Ley $N^{\circ} 20.123$, cit. (n. 24), pp. 870 s. A lo dicho hay que agregar que si se estima que el artículo $183 \mathrm{AB}$ del Código del Trabajo consagra una hipótesis de responsabilidad directa legal, para resolver el problema recién expuesto sería útil determinar cuál es la responsabilidad de derecho común en derecho chileno, pues precisamente el régimen al cual se le atribuya dicha calidad (contractual o extracontractual) es el llamado a regular los aspectos no resueltos en las particulares hipótesis de responsabilidad legal. Sin embargo, este razonamiento nos lleva también a un problema arduamente debatido en derecho nacional, y en que hasta hoy existen posiciones divergentes (Un detallado tratamiento del estado actual de este problema en nuestro derecho en: Alonso Traviesa, María Teresa, El problema de la concurrencia de responsabilidades (Santiago, LexisNexis, 2006), pp. 86-147; BARros BourIE, Enrique, Tratado de responsabilidad extracontractual (Santiago, Editorial Jurídica de Chile, 2006) pp. 1.067-1.071). 
enero de 2006) se ha introducido en nuestro país un nuevo procedimiento laboral que gradualmente está entrando en vigencia en nuestro país.

De los varios aspectos relevantes de dicha normativa con incidencia en esta materia (que merecen un tratamiento específico en otra oportunidad), cabe destacar la interesante regla contenida en el artículo 447 CT. que esta Ley introduce al Código del Trabajo, el cual dispone que: "El juez declarará de oficio cuando se estime incompetente para conocer de la demanda, en cuyo caso asi lo declarará, señalará el tribunal competente, y le enviará los antecedentes".

Su importancia radica en que un cumplimiento estricto de esta regla desde el inicio de los pleitos por parte de los jueces laborales podría, al menos, evitar inútiles sustanciaciones y dilaciones para las partes ${ }^{34}$, más aun considerando las incertezas y dificultades que se presentan para las partes en la fijación de la jurisdicción competente para conocer de acciones indemnizatorias derivadas de accidentes del trabajo o enfermedades profesionales.

\section{LAS NOVEDADES JURISPRUDENCIALES}

De nuestra jurisprudencia más reciente deben destacarse los siguientes aspectos en relación con la responsabilidad civil derivada de accidentes del trabajo y enfermedades profesionales.

\section{La supervivencia del artículo 64 del "Código del Trabajo" y sus nuevas} interpretaciones.

Un primer aspecto que merece ser destacado en este punto es que varias sentencias recientes han seguido aplicando el derogado artículo 64 CT., en el entendido, pensamos (pues no se ha hecho mayor fundamentación al respecto), que tratándose de acciones deducidas por trabajadores con contratos de trabajo celebrados cuando dicha norma estaba vigente cobra

${ }^{34}$ Ello por cuanto no han sido pocas las ocasiones en que la incompetencia absoluta para conocer de acciones indemnizatorias derivadas de accidentes del trabajo ha sido declarada recién de oficio por la Corte Suprema, luego de inútiles tramitaciones y dilaciones para las partes. Así por ejemplo pueden verse las sentencias de Corte Suprema, de 17 de noviembre de 2003, rol No 3337-2002; de 11 de mayo de 2004, rol No 2610-2003; de 28 de septiembre de 2005, rol No 1591-2004; de 29 de septiembre de 2005, rol No 2606-2004; y de 25 de enero de 2006, rol No 3493-2004, en todas las cuales la Excma. Corte anuló de oficio todo lo obrado en dichos procesos por la jurisdicción laboral, a partir de la resolución que proveyó la demanda en adelante, en el entendido que por tratarse de acciones indemnizatorias deducidas por víctimas por repercusión por su daño propio la competencia absoluta correspondía a la justicia civil. 
vigencia el artículo 22 de la Ley sobre efecto retroactivo de las leyes, el cual dispone que "en todo contrato se entenderán incorporadas las leyes vigentes al tiempo de su celebración" 35 .

Y de entre estas sentencias, la mayoría continúa entendiendo que la "responsabilidad subsidiaria" contemplada en el derogado artículo 64 se extiende al pago de las indemnizaciones por accidentes del trabajo o enfermedades profesionales causados por dolo o culpa del contratista o subcontratista ${ }^{36}$.

Sin embargo existen ciertos fallos en que se comienza a esbozar un importante cambio jurisprudencial.

Así, en al menos un par de sentencias del año 2007 nuestra propia Corte Suprema ha dicho en esta materia que "la responsabilidad subsidiaria posee limites" y ello "desde un doble punto de vista, tanto jurídico como fáctico". Respecto de lo primero "uno de los límites de la responsabilidad subsidiaria, está establecido en el propio inciso final del artículo 64 del Código del Trabajo, en cuanto no la extiende al caso de construcción de edificios por un precio único prefijado, encargada por una persona natural", en tanto que "desde un ángulo práctico, la responsabilidad en examen debe estimarse comprensiva sólo de los casos en que el dueño de la obra, faena o empresa ha podido fiscalizar el cumplimiento por parte del contratista o subcontratista de las obligaciones de las que se pretende hacerlo responsable" ${ }^{37}$.

Las consideraciones reseñadas llevaron a rechazar, en un caso, la acción deducida en contra de la "demandada subsidiaria", acreditado en el proceso que el "empleador directo del actor" fue quien "dio la orden de usar la escalera en la reparación de las luminarias, lo que estaba expresamente probibido por la demandada subsidiaria", razón por la cual se concluye que "no es posible

${ }^{35}$ La solución descarta así tácitamente en esta materia la aplicación in actum de las reformas laborales sustanciales que sobre tercerización en las relaciones del trabajo introdujo la Ley $\mathrm{N}^{\circ}$ 20.123. Pero ello ameritaba, en nuestro concepto, reflexiones mayores pues en otras ocasiones se ha estimado que reformas sustanciales laborales sustanciales rigen desde que la correspondiente ley que las incorpora entra en vigencia.

${ }^{36}$ Así por ejemplo: Corte de Apelaciones de Santiago, 23 de agosto 2007, rol N ${ }^{\circ}$ 1051-2007; Corte de Apelaciones de Concepción, 24 de septiembre de 2007, rol $\mathrm{N}^{\circ}$ 138-2007; Corte de Apelaciones de Chillán, 6 de noviembre de 2007, rol $\mathrm{N}^{\circ}$ 70-2007; y Corte de Apelaciones de Concepción, 4 de diciembre de 2007, rol N ${ }^{\circ}$ 405-2007.

${ }^{37}$ Así: Corte Suprema, 31 de mayo de 2007, rol No 5830-2005, considerando $8^{\circ}$ (recordando al efecto que "ya se resolvió en materias similares que si ello escapaba de la esfera de control del responsable subsidiario, éste no puede ser condenado en tal calidad") y Corte Suprema, 24 de septiembre de 2007, rol No 748-2006, en LexisNexis $\mathrm{N}^{\circ}$ identific. 37298 , considerando $16^{\circ}$. 
atribuir a la dueña de la obra o faena-la recurrente de casación- responsabilidad subsidiaria en la condena que se le ha impuesto al contratista por infringir el deber de seguridad, desde que aquélla no estuvo en condiciones reales de ejercer una fiscalización mayor que la que hizo operar en relación con el cumplimiento de las medidas que tendieran a proteger eficazmente la vida y seguridad de los trabajadores de la obra o faena contratada" 38 .

Por el contrario, en otra ocasión las mismas consideraciones sirvieron para resolver que si "las labores se ejecutaban en el lugar en que desarrollaba sus actividades la empresa demandada [subsidiaria], en el cual le es exigible mantener un control tanto de acceso como de las acciones que se ejecutan en su interior" se debe concluir que "es posible atribuir a la dueña de la obra o faena-la recurrente de casación- responsabilidad subsidiaria en la condena que se le ha impuesto a la contratista por infringir el deber de seguridad, desde, que aquélla estuvo en condiciones reales de ejercer una fiscalización mayor que la que hizo operar en relación con el cumplimiento de las medidas que tendieran a proteger eficazmente la vida y seguridad de los trabajadores de la obra of faena contratada" 39 .

2. La reciente aceptación de la tesis de la intransmisibilidad de la acción indemnizatoria por daño moral.

Otro aspecto importante a destacar en nuestra jurisprudencia reciente, lo constituyen ciertos pronunciamientos que han comenzado a sostener la intransmisibilidad de la acción indemnizatoria por daño moral en este sector, contradiciendo así una fuerte tendencia jurisprudencial ${ }^{40}$ y doc-

${ }^{38}$ Corte Suprema, 31 de mayo de 2007, rol N 5830-2005, acogiendo así el recurso de casación en el fondo deducido al efecto al entenderse que "los sentenciadores interpretaron con error de derecho la norma del artículo 64 del Código del Trabajo, al extender la responsabilidad subsidiaria del dueño de la obra o faena a una situación de hecho no prevista por aquella".

${ }^{39}$ Corte Suprema, 24 de septiembre de 2007, rol No $748-2006$, en LexisNexis $\mathrm{N}^{\circ}$ identific. 37298.

${ }^{40}$ Así, por ejemplo, sosteniendo la transmisibilidad de la acción indemnizatoria por daño moral en otros sectores de responsabilidad civil: Corte de Apelaciones de Concepción, 15 de diciembre de 2004, rol No 2074-2004 (donde se sostuvo que: "la madre del recluso fallecido, como heredera de su hijo, puede legitimamente ejercitar la acción reparatoria que ha promovido por el sufrimiento, aflicción y angustia que padeció su descendiente desde que fue recapturado y golpeado tras el intento de fuga hasta el instante de su muerte. No se puede justificar la ausencia de dolor en estado de inconsciencia. El dolor inmaterial está presente en el ser vivo herido, consciente o no, como sombra al cuerpo. El desarrollo de los ciclos de vida en los estados vegetales así lo demuestran. El alma sufre cuando el cuerpo sufre. El hombre es un conjunto de sistemas que le dan vida, pero algo más. Ninguna inteligencia podría negarlo"); Corte de Apelaciones de Concepción, 26 de abril de 2006, rol No 4825-2003, (aunque distinguiendo si la víctima del delito o 
trinaria ${ }^{41}$ precedente y que había generado repercusiones importantes en esta materia, pues -como se ha visto- llevó a admitir en sede laboral las demandas indemnizatorias deducidas por causahabientes de trabajadores muertos en accidentes del trabajo que accionando iure hereditatis buscaban obtener el resarcimiento del daño moral que el causante habría experimentado antes de morir y cuya acción indemnizatoria les habría transmitido al momento de fallecer.

En apoyo de la tesis de la intransmisibilidad de esta acción recientes sentencias han argumentado que el resarcimiento del daño moral tiene por objeto "compensar el mal soportado por la víctima, personalmente"

cuasidelito fallece instantáneamente o con posterioridad a él, aceptando la transmisibilidad sólo para esta última hipótesis). En todo caso, un pronunciamiento contrario a la transmisibilidad de la acción indemnizatoria por daño moral se encuentra en: Corte de Apelaciones de Santiago, 2 de noviembre de 2005, sentencia pronunciada por la Cuarta Sala integrada por los ministros Alfredo Pfeiffer, Cornelio Villarroel y el abogado integrante Hugo Llanos Mansilla, en autos rol No 27271-2002.

${ }^{41}$ Doctrinariamente aceptan la transmisibilidad: ALESSANDRI RodRíGUEZ, Arturo, De la responsabilidad extracontractual en el Derecho Civil chileno (Santiago, Editorial Universitaria, 1943) No 388 pp. 467-468; Bidart Hernández, José Pascal, Sujetos de la acción de responsabilidad extracontractual (Santiago, Editorial Jurídica de Chile, 1985), p. 92; Rodríguez Grez, Pablo, Responsabilidad extracontractual (Santiago, Editorial Jurídica de Chile, 1999), pp. 366-368 (incluso en las, mal llamadas a su entender, "muertes instantáneas"); y, recientemente, BARRIENTOS ZaMORANO, Marcelo Heriberto, La transmisibilidad de la acción por daño moral en el Derecho privado europeo, en La Semana Jurídica 218 (semana del 10 al 16 de enero de 2005), pp. 14-16 (quien consigna que "la generalidad de los ordenamientos jurídicos europeos descarta la transmisibilidad iure hereditatis en los casos de muerte coetánea al accidente y la admite de ordinario, cuando la muerte no es simultánea" (p. 15), concluyendo que "la muerte no puede ser sino un acto de vida, y como tal, el daño moral sufrido en ella, es transmisible, el que además quedaría aumentado o agravado por el conocimiento del mismo" (p. 16). Una autorizada autora sostuvo recientemente que, pese a existir ciertas objeciones desde el punto de vista ético, "la transmisibilidad de la acción por daño moral no ejercitada por el causante no parece discutirse en la actualidad. Su carácter personalísimo no es uniformemente admitido, porque tiene un contendido económico evidente, ya que la reparación habrá de traducirse en indemnización dineraria, salvo los casos de otras formas de reparación, por ejemplo del derecho al honor, que además no excluyen la indemnización económica. Y, en definitiva, no hay objeciones técnicas para someterla al sistema general de transmisibilidad de los derechos y acciones del causante. En derecho comparado latino, es ésta una cuestión que en el presente ya no merece dudas y esa es la doctrina seguida en nuestro derecho", Domínguez Hidalgo, Carmen, El daño moral (Santiago, Editorial Jurídica de Chile, 2000), II, p. 731. Por la intransmisibilidad de esta acción véase: Domínguez Águila, Ramón, Sobre la transmisibilidad de la acción por daño moral, en Revista Chilena de Derecho 31 (Santiago, Pontificia Universidad Católica de Chile, 2004) 3, pp. 493-514. 
lo que "sólo se cumple, entonces, cuando la reparación es entregada al que padeció el dolor, la molestia o aflicción en sus sentimientos o facultades espirituales", que esta posición "armoniza con el tenor del artículo 88 de la Ley No 16.744" precepto que establece que: "Los derechos concedidos por la presente ley son personalísimos e irrenunciables", calificación, la primera, que impediría "su transferencia y transmisión", recordándose además en este sentido las opiniones de los profesores Enrique Barros Bourie y Carmen Domínguez Hidalgo ${ }^{42}$.

De imponerse esta tendencia prácticamente se eliminará la posibilidad que la justicia laboral pueda conocer de acciones resarcitorias derivadas de muertes de trabajadores a consecuencia de accidentes del trabajo o enfermedades profesionales ${ }^{43}$.

Si bien no es la oportunidad para analizar en detalle el problema de la transmisibilidad de la acción indemnizatoria por daño moral, dejaremos al menos planteada la duda acerca de cómo se compatibilizará esta solución de los tribunales chilenos con lo resuelto por la Corte Interamericana de Derechos Humanos, en cuyos fallos se leen afirmaciones tan directas como que: "La Corte ha indicado, y lo reitera ahora, que el derecho a la indemnización por los daños sufridos por las víctimas hasta el momento de su muerte se transmite por sucesión a sus herederos. Por el contrario, los daños provocados a los familiares de la victima o a terceros por su muerte pueden ser reclamados fundándose en un derecho propio" ${ }^{44}$.

\section{PALABRAS FINALES}

Hecha entonces esta revisión de reformas normativas y de cambios jurisprudenciales operados en nuestro país en tiempos recientes, esperamos al menos haber mostrado una serie de nuevos problemas que afectan hoy a la responsabilidad civil derivada de accidentes del trabajo y enfermedades

${ }^{42}$ Corte Suprema 27 de junio de 2007, rol No 309-2006 (especialmente considerandos $9^{\circ}$ a $13^{\circ}$ ). En el mismo sentido: Corte Suprema, 27 de noviembre de 2007, rol N 6196-2006 y Corte de Apelaciones de Concepción, 12 de diciembre de 2007, rol No $423-2007$.

${ }^{43}$ En efecto, en este caso sólo podría accederse a la justicia laboral cuando los causahabientes del trabajador fallecido accionen iure hereditatis respecto de los eventuales daños materiales que el trabajador pudiera haber experimentado antes de morir.

${ }^{44}$ Sentencia de 27 de noviembre caso "Castillo Páez contra la República del Perú", citada en: NASH RojAS, Claudio, Las reparaciones ante la Corte Interamericana de Derechos Humanos (Santiago, Universidad de Chile, Centro de Derechos Humanos, 2004), pp. 204 y 205; pudiendo verse también la demás jurisprudencia transcrita al respecto entre las páginas 196 a 215 de esa obra. 
profesionales, y a cuya resolución se abocarán seguramente en lo sucesivo los esfuerzos teóricos y prácticos.

[Recibido el 3 y aceptado el 14 de noviembre de 2008].

\section{BIBLIOGRAFÍA}

Alessandri Rodríguez, Arturo, De la responsabilidad extracontractual en el Derecho Civil chileno (Santiago, Editorial Universitaria, 1943).

Alonso Traviesa, María Teresa, El problema de la concurrencia de responsabilidades (Santiago, LexisNexis, 2006).

BidART HERnÁNDEZ, José Pascal, Sujetos de la acción de responsabilidad extracontractual (Santiago, Editorial Jurídica de Chile, 1985).

Barrientos Zamorano, Marcelo Heriberto, La transmisibilidad de la acción por daño moral en el derecho privado europeo, en La Semana Jurídica 218 (semana del 10 al 16 de enero de 2005).

Barros Bourie, Enrique, Tratado de responsabilidad extracontractual (Santiago, Editorial Jurídica de Chile, 2006).

Diez SCHWERTER, José Luis, La culpa del empresario por accidentes del trabajo: modernas tendencias jurisprudenciales, en Cuadernos de Extensión Jurídica 10 (Santiago, Universidad de los Andes, 2005).

Diez SChWerter, José Luis, Victimas directas y por repercusión en la responsabilidad civil derivada de accidentes del trabajo o enfermedades profesionales en nuestra jurisprudencia reciente: del problema de la competencia a las distorsiones sustanciales, en Revista de Derecho 214 (Concepción, Universidad de Concepción, 2003 [pero 2005]), pp. 65-79, ahora, en Varas Braun, Juan Andrés - Turner Saelzer, Susan (coordinadores), Estudios de Derecho Civil. Jornadas Nacionales de Derecho Civil Valdivia 2005 (Santiago, LexisNexis, 2005), pp. 563-583

Diez SCHWERTER, José Luis, Responsabilidad civil por muertes en accidentes del trabajo: vacilaciones que persisten, en Corral Talciani, Hernán - Rodríguez Pinto, María Sara (coordinadores), Estudios de Derecho Civil (Santiago, LexisNexis, 2007), II, pp. 421-430.

Domínguez ÁGuila, Ramón, con la colaboración de Escalona Riveros, Francisco, La prescripción extintiva. Doctrina y jurisprudencia (Santiago, Editorial Jurídica de Chile, 2004).

Domínguez Águila, Ramón, Comentarios de Jurisprudencia, en Revista de Derecho 206 (Concepción, Universidad de Concepción, julio-diciembre 1999) [pero diciembre de 2000]), pp. 165-169.

Domínguez Águila, Ramón, Comentarios de Jurisprudencia: 1.- Competencia civil para el conocimiento de la acción indemnizatoria del daño moral sufrido por causahabientes del trabajador, en Revista de Derecho 211 (Concepción, Universidad de Concepción, 2002 [pero abril de 2004]), pp. 259-265.

Domínguez Águila, Ramón, Sobre la transmisibilidad de la acción por daño moral, en Revista Chilena de Derecho 31 (Santiago, Pontificia Universidad Católica de Chile, 2004) 3, pp. 493-514.

Domínguez Hidalgo, Carmen, El daño moral (Santiago, Editorial Jurídica de Chile, 2000). 
Gamonal Contreras, Sergio, Fundamentos de Derecho Laboral (Santiago, LexisNexis, 2008).

LANata Fuenzalida, Ruth Gabriela, El contrato de trabajo como negocio jurídico en la legislación chilena (tesina de maestría en Derecho privado, Rosario, Universidad Nacional de Rosario, 2007).

NASH Rojas, Claudio, Las reparaciones ante la Corte Interamericana de Derechos $\mathrm{Hu}$ manos (Santiago, Universidad de Chile, Centro de Derechos Humanos, 2004), pp. 204 y 205.

Peña González, Carlos y Pizarro Wilson, Carlos, Informe en Derecho sobre la responsabilidad subsidiaria del dueño de la obra, en Revista Chilena de Derecho Privado 2 (2004), pp. 152-162.

Peñailillo Arévalo, Daniel, Las obligaciones. Teoría general y clasificaciones. La resolución por incumplimiento (Santiago, Editorial Jurídica de Chile, 2003).

Plá Rodríguez, Américo, Los principios del Derecho del Trabajo (Buenos Aires, Depalma, 1998).

Prado López, Pamela, Crítica a la configuración de la responsabilidad civil de la empresa principal y de la empresa usuaria en la Ley $N^{\circ} 20.123$, en GUZMÁN BRITO, Alejandro (editor científico), Estudios de Derecho Civil III. Jornadas Nacionales de Derecho Civil Valparaíso 2007 (Santiago, Legal Publishing, 2008), pp. 857-872.

Rodríguez Grez, Pablo, Responsabilidad extracontractual (Editorial Jurídica de Chile, Santiago, 1999).

Ugarte Cataldo, José Luis, El nuevo Derecho del trabajo, (Santiago, Legal Publishing, 2008).

Zelaya Etchegaray, Pedro, Responsabilidad subsidiaria del dueño de obra por los accidentes y daños experimentados por el trabajador del contratista, en Cuadernos de Extensión Jurídica 10 (Santiago, Universidad de los Andes, 2005) pp. 99-122.

Zelaya Etchegaray, Pedro, Responsabilidad subsidiaria del dueño de la obra, empresa $o$ faena por los daños causados al trabajador de contratista o subcontratista (Naturaleza y extensión de la responsabilidad del artículo 64 del Código del Trabajo: un análisis dogmático y jurisprudencial), en Revista de Derecho y Jurisprudencia 101 (Santiago, 2004) 2, $1^{\text {a }}$ parte, pp. 25-44. 
